\title{
Antonio Preciado: Entre la Ciudad Letrada y las memorias ancestrales
}

\section{Artículo de investigación}

\section{Javier Eduardo Pabón}

Saint Augustine's University, USA

jepabon@st-aug.edu

Recibido: 20 de abril de 2017

Aprobado: 12 de junio de 2017

Cómo citar este artículo: Pabón, Javeir Eduardo. (2018) Antonio Preciado: Entre la Ciudad Letrada y las memorias ancestrales. Calle14: revista de investigación en el campo del arte, 13 (23) pp. 210-223

DOI: pendiente 


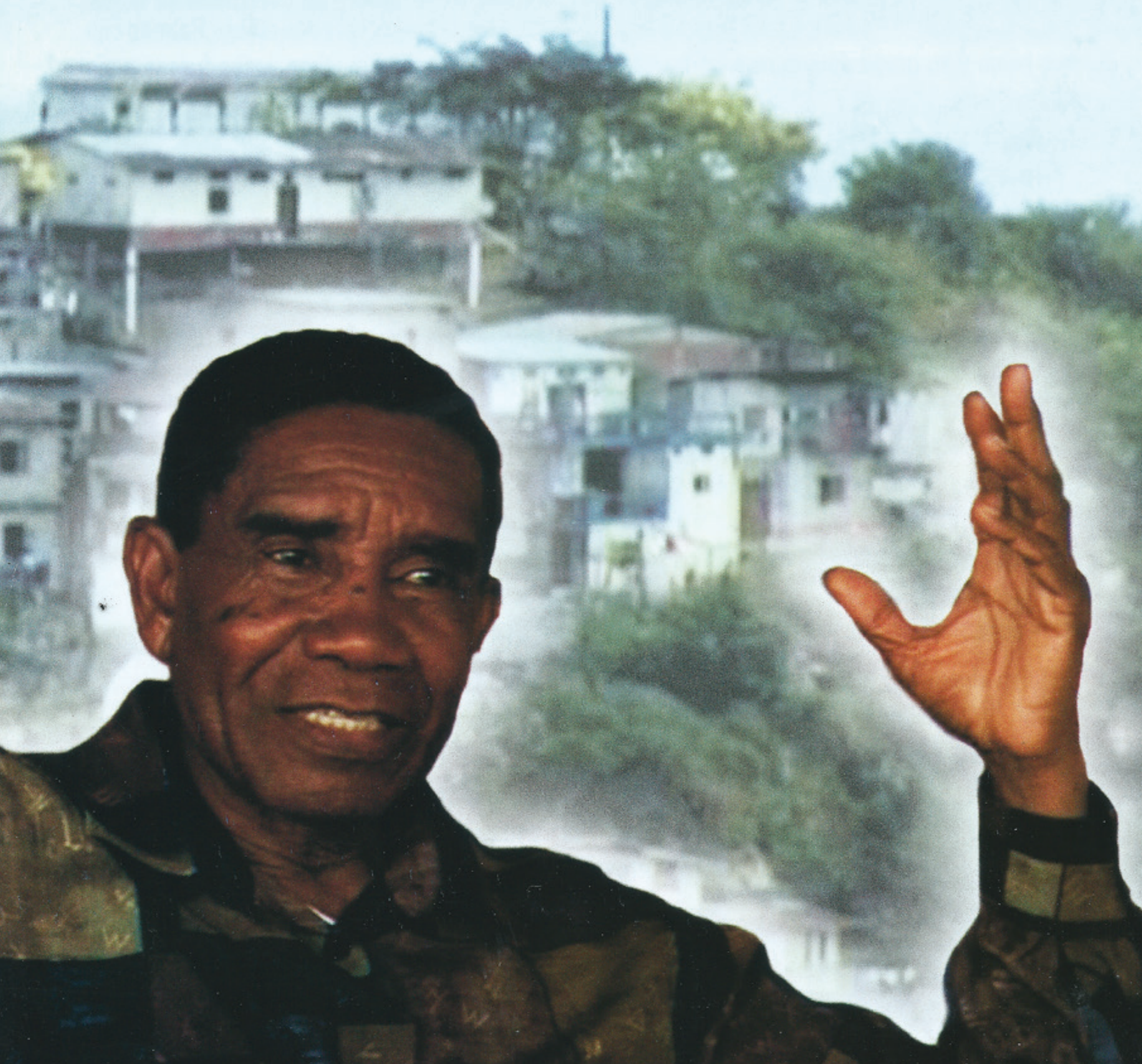




\title{
Resumen
}

Este artículo indaga las tensiones entre la obra del poeta ecuatoriano Antonio Preciado, frente a ciertas categorizaciones en el análisis y la producción literaria de los hijos de la diáspora. El análisis persigue un posicionamiento para desarrollar herramientas teóricas orientadas en los procesos de descolonización de la interpretación literaria y de los saberes, cuyo valor trasciende lo particular y la estereotipación sobre lo "Afro". Intenta, también, hacer una lectura que compare distintos posicionamientos históricos y teóricos, que permitan dialogar con la producción poética de Preciado, en su negociación y entendimiento del ejercicio literario.

\section{Palabras claves}

Poesía, decolonialidad, canon literario.

Antonio Preciado: between the literate city and ancestral memories

\begin{abstract}
This article delves in the tensions in the work of the Ecuadorian poet Antonio Preciado facing certain categorizations in the analysis and the literary production of the children of the diaspora. The analysis pursues a position to develop guided theoretical tools in the processes of decolonization of the literary interpretation and of knowledge, whose value transcend the particular and the stereotyping of the "Afro". It also tries to make a reading that compares different historical and theoretical positions, allowing a dialogue with the poetic production of Preciado, in his negotiation and understanding of the literary exercise.
\end{abstract}

\section{Keywords}

Poetry, decoloniality, literary canon.

Antonio Preciado: entre la cité lettrée et les souvenirs ancestraux

\section{Résumé}

Cet article se penche sur les tensions dans le travail du poète équatorien Antonio Preciado face à certaines catégorisations dans l'analyse et la production littéraire des enfants de la diaspora. L'analyse poursuit une position pour développer des outils théoriques guidés dans les processus de décolonisation de l'interprétation littéraire et de la connaissance, dont la valeur transcende le particulier et le stéréotype de « l'afro ». Il essaie aussi de faire une lecture qui compare différentes positions historiques et théoriques, permettant un dialogue avec la production poétique de Preciado, dans sa négociation et sa compréhension de lıexercice littéraire.

\section{Mots clés}

Poésie, décolonialité, canon littéraire.

Antonio Preciado: entre a cidade literata e as memórias ancestrales

\section{Resumo}

Este artigo aprofunda as tensões no trabalho do poeta equatoriano Antonio Preciado enfrentando certas categorizações na análise e na produção literária dos filhos da diáspora. A análise persegue uma posição para desenvolver ferramentas teóricas guiadas nos processos de descolonização da interpretação literária e do conhecimento, cujo valor transcende o particular e o estereótipo do "Afro". Também tenta fazer uma leitura que compara diferentes posições históricas e teóricas, permitindo um diálogo com a produção poética de Preciado, na sua negociação e compreensão do exercício literário. 


\section{Palavras-chave}

Poesia, descolonialidade, cânone literário.

\section{Antonio Preciado, sug alpa luar suti puglu letrada i iuiaikuna antiwamandakaska}

\section{Maillallachiska:}

Kai kilkaikunapi tapurimi sug runa ecuatoriano Antonio Peciado, chasa kawachhirispa i iuiarispa imasami mirarka kai tsabajukuna sug wambra suti diáspora. Chasaiatata iuiarimi imasami Tukui herramienta rurarirka i kai imasami sug kilkaskapi iachariska sapaia kagta sug "ianakuna" chasami kaiari rurangapa sug vircial kilkaskata antiwamanda i parlarimi kai sirsialkunamanda kai suti runa preciadomanda chasa mana nigpika i allilla kaskata ruraska kai imasami sug iura pangapi kilkaska.

\section{Rimangapa Ministidukuna:}

Virsiai, mana kai alpa kaskamanda, canon kilkaska. 


\section{El poeta de Barrio Caliente en La ciudad letrada}

La obra de Antonio Preciado puede ser vista desde varias perspectivas. La primera es la de un poeta "a secas", que es la visión que él prefiere. La segunda propuesta, ubicaría su poesía como la de un ecuatoriano que es parte de la ciudad letrada latinoamericana. Finalmente, y para problematizar, podríamos enmarcar su opus literario dentro de una tradición que podemos llamar afrodescendiente. Ninguna de estas aproximaciones es totalmente adecuada o completa y, por lo tanto, hay que asumir la necesidad de transitar entre ellas, siguiendo los pasos y las rimas de sus versos. Se trata de una tensión muy familiar entre quienes analizan las representaciones que han sido subordinadas por el orden dominante tal como lo advierte el investigador Richard Iton: "¿Cómo se involucran los excluidos con un orden dominante? ¿Acaso el progreso significa que los marginados acepten normas de las corrientes dominantes y abandonen las posibilidades de transformación política?" (Iton, 2008: 3). Si bien Antonio Preciado es un poeta reconocido internacionalmente, propongo que su voz procede de una experiencia que se descentra del lugar de enunciación privilegiado por la sociedad ecuatoriana, es decir, la visión blanco-mestiza y por ello posee un valor añadido al literario. Más aun, su desgarramiento frente a esas preguntas permitirá comprender hasta qué punto el descentramiento del orden dominante puede mantener posibilidades transformativas $y$, en consecuencia, oportunidades políticas y propuestas literarias muy específicas.

En el texto "Antonio Preciado, poeta de la diáspora", Michael Handelsman destaca un testimonio esclarecedor sobre la visión del poeta y su propia obra. De una entrevista hecha en el año 2010 Handelsman comenta lo siguiente:

Antonio Preciado Bedoya (Esmeraldas, 1941) expresó categóricamente su desacuerdo con todo intento de categorizarlo como poeta negro o afro y, además, rechazó el valor de las antologías dedicadas estrictamente a escritores afros, señalando que tales proyectos solamente contribuían a marginar a dichos escritores del canon literario, sea éste nacional o latinoamericano. De hecho, Preciado volvió a insistir varias veces que él es un poeta sin calificativos-"a secas", como quien dice-dedicado a escribir una literatura para todos. Pero, curiosamente, en esta misma conversación él fue igualmente categórico al reconocer su identidad y herencia como afrodescendiente, producto del Barrio Caliente de Esmeraldas, Ecuador. Más que una contradicción de conceptos, este doble posicionamiento de Preciado frente a su condición de poeta, por un lado, y afrodescendiente por otro, se remite a una larga historia de la diáspora africana en las Américas (Handelsman, 2011: 133).

Esta aparente contradicción hace pertinente que este trabajo reflexione en la evolución de la "mirada" hacia lo afro en el Ecuador, pero, además, que considere que en sus conclusiones es posible superar las visiones existentes y arribar, de ser posible, a otras más novedosas.

En otro estudio, este sobre el escritor esmeraldeño Nelson Estupiñán Bass, Handelsman define algunos parámetros que han caracterizado el análisis que hasta ahora ha hecho de la literatura afrolatinoamericana:

Ya se sabe que la literatura de y por los afros ha pasado por tres etapas rectoras, a saber: el negrismo, la negritud y el afrocentrismo. Según nuestra lectura, esta trayectoria histórica se explica mediante aquella referencia al pensar sobre/desde/con. Es decir, mientras que el primer caso implica una jerarquización propia de la colonialidad, el segundo sugiere un acercamiento fundamentado en los conocimientos aprendidos del contacto directo $y$, finalmente, pensar con se refiere a las relaciones dialogales que, a diferencia de los anteriores casos caracterizados siempre por una voz de poder y autoridad, hacen posible la representación propia de los diferentes grupos sociales tan necesaria para una verdadera democratización (Handelsman, 2011: 5).

Siguiendo esta clasificación, propongo que este trabajo haga un diálogo con, orientado por la categoría que Juan García denomina "casa adentro". La equivalencia entre "afrocentrismo" $y$ "casa adentro" es una que aún no ha sido saldada definitivamente, precisamente porque el "afrocentrismo", como categoría de análisis, tiene un origen distinto que la noción de "casa

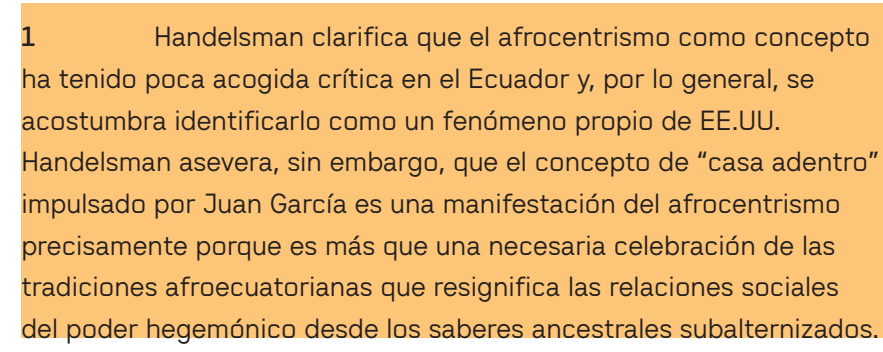


adentro", propuesta desde las comunidades. No obstante, dejando constancia de esta tensión, me permito el uso de estas categorías para así poder contrastarlas. Al hacerlo, propongo una lectura de la obra de Antonio Preciado desde una perspectiva que respete la voluntad del autor de autorreconocerse como poeta (a secas) y una lectura que busca entrar en conversación con él y su obra, entendiendo la conversación en su significado más primario, es decir, una extensión del término latín conversio, que significa un retorno, un cambio de dirección, una conversación que ayude a aproximarse a su poesía y a la experiencia de los descendientes de la diáspora en el Ecuador.

El mismo Preciado reconoce el posicionamiento múltiple pues, por un lado, busca desasociarse de membretes que considera inútiles y que separan su obra en un subgénero literario distinto del canon nacional. Al hacerlo, se previene frente al riesgo de que tal distinción esté contaminada por el racismo inscrito en la mirada blanco-mestiza. Al mismo tiempo, Preciado es un esmeraldeño jututo², orgulloso de su herencia ancestral y parte activa de su comunidad, como él mismo lo reconoció en la entrevista antes citada: "(...) él fue igualmente categórico al reconocer su identidad y herencia como afrodescendiente, producto de Barrio Caliente de Esmeraldas, Ecuador" (Handelsman, 2011: 112).

La problematización que hace Preciado sobre el canon identifica el riesgo que implica marginar lo que ya está marginado, haciéndolo aún más distante y acaso exótico. No obstante, desde la afirmación de Linda Tuhiwai Smith cuando dice: "La idea de occidente se vuelve realidad cuando ésta se re-presentó a las naciones indígenas a través del colonialismo," (Tuhiwai Smith, 2012: 61) se puede concluir que es un ejercicio legítimo desestabilizar los cánones literarios, cuestionando los regímenes de verdad y de re-presentación en el concepto occidental de lo literario. Tuhiwai Smith nos recuerda que "las formas de disciplinar fueron la exclusión, la marginalización y la negación de los saberes indígenas". (Tuhiwai Smith, 2012: 62). Por lo tanto, una forma de desmarcarse es impregnar la "disciplina" con saberes otros -indígenas, afros, femeninos, queer, subalternos - para afirmarlos gozosamente contra las "formas canónicas de dominación". Tal posicionamiento es necesidad e impulso y busca enfrentarse al borramiento implícito en la narrativa única del mestizaje. Comparo esta encrucijada con la que Preciado enfrenta como autor literario que es frecuentemente encasillado

2 Auténtico. dentro de la tradición afrolatinoamericana. Al hacerlo, quiero mantener en mi horizonte teórico una de las frases seminales del recientemente fallecido Stuart Hall, "política sin garantías". Con este postulado Hall se opone al esencialismo y problematiza la noción genética de raza que asume que:

(...) raza es una característica biológica fija y que un gran número cosas: rasgos culturales, rasgos intelectuales, rasgos emocionales y expresivos obedecen al hecho de pertenecer genéticamente a una raza u otra. Si esta es su conceptualización, usted pensará que el mero hecho de pertenecer a una raza efectivamente garantiza un gran número de cosas, incluyendo que una obra de arte es buena o mala por ser producida por una persona que biológicamente pertenece a esa raza (Hall, 1997: 4).

Una lectura desde el ámbito de una "política sin garantías" desarticula cualquier noción de que la obra de arte de un afrodescendiente es valiosa porque proviene de las manos de un sujeto descendiente de esclavizados $y$, por ello, es parte de un proyecto político emancipatorio y antirracista por el simple hecho de ser el trabajo de una persona de color. En estas condiciones se plantea un diálogo que reconoce la subjetividad que se posiciona política y existencialmente en un locus liminar y fluctuante que sea crítico.

Suenan con fuerza las palabras de Preciado de que "la poesía no tiene color" y las de Glissant: "para las gentes colonizadas identidad será principalmente 'opuesto a'-es decir, una limitación desde el principio. La decolonización solo será real cuando supere este límite" (Glissant, 1997: 18). Aunque la afirmación de Preciado es respetable, y quizás su poesía no se agote en su negritud, las instituciones nacionales y globales que la juzgan han racializado al poeta y a su producción simbólica desde su lógica. La valoración ya ha sido hecha, como Sylvia Wynter oportunamente define:

(...) nuestras jerarquías socio-sistémicas globales y estado-nacionales son, por tanto, la expresión no de categorías prescriptivas de nuestro modelo epistémico cultural global, sino, en última instancia, la evolución de grados eugénicos de "valía" pre-seleccionados entre grupos humanos a nivel de raza, cultura, religión, clase, etnicidad, sexualidad, y sexo (Wynter, 1994: 54).

La lírica de Preciado no se contiene en su negritud, pero muchas de sus lecturas sí. Más aun, se encuentra 
entrecruzada por tensiones que se pueden entender considerando la interseccionalidad entre raza, clase, género y sexualidad. La interseccionalidad se configura como una categoría teórica propuesta por las feministas de color que permite entender la superposición, unión, choque -intencionales o no- de los distintos factores de privilegio y opresión que como sujeto afectan a Preciado y a sus lectores. Como lo explica María Lugones, la interseccionalidad se expresa en una trama, una urdimbre imposible de separar:

(...) casi todos los términos presuponen la separación cuando lo que se está tratando de expresar es precisamente la inseparabilidad, fusión, coalescencia (un término de la química). Por ese problema, a lo largo de mi trabajo he dejado de lado “interconexión”, “entrelazado", "entrecruzado". El interconectar o entrecruzar a veces oculta la inseparabilidad y los términos como inseparables. Términos como "urdimbre" y "entretrama" me gustan porque expresan la inseparabilidad de una manera interesante: al mirar el tejido la individualidad de las tramas se vuelve difusa en el dibujo o en la tela (Lugones, 2008: 79).

La "inseparabilidad" a la que refiere Lugones puede ser leída como un rasgo principal de la interculturalidad crítica, la misma que rechaza el borramiento de la diferencia que supone la homogenización mediante las identidades estereotipadas y estables. En el entramado, Preciado pareciera entender junto a Stuart Hall que no se pueden fijar "los méritos de un trabajo literario o musical, o la corrección de una actitud o creencia, en una conexión explicada y fijada a la verdad por el carácter racial de la persona en ella envuelta". (Hall, 1997: 7). Preciado no pretende desasociarse de su raza, de su masculinidad, de su ecuatorianidad, de su perspectiva sociocultural, en otras palabras, de su experiencia de vida. De allí que, aunque sea de manera no intencional, los poemas de Preciado están cargados de potencial decolonizador debido precisamente a las subalternidades que lo componen.

La conversación con el poeta y con su obra estará marcada por una urdimbre de factores y posicionamientos que generan tensiones y desgarramientos que se extienden a los territorios simbólico y físico. Desgarramientos que llegan incluso a superar fronteras, que cruzan la "raya", es decir, la separación política entre Ecuador y Colombia, que históricamente ha sido irrelevante para los habitantes de la región Pacífica, tal como lo afirma Juan García:
En el tiempo que nosotros nos criamos esto de colombianos y ecuatorianos era una cosa que casi no se tenía en cuenta, la gente caminaba costa arriba, costa abajo buscando su madre de Dios (...) Para nuestros mayores, saber de qué familia era una persona, era más importante que esto de ser de este lado o del otro de la frontera (...) por lo menos los que somos negros, hemos sido y todavía somos como una sola familia (Abad, 2013: 91).

Pero esta no es la única raya, conviene considerar la "línea del color" de la que hablara Du Bois, que no se limita al color de la piel, sino que incluye muchas otras dimensiones identitarias. Así lo propuso el escritor dominicano Junot Díaz en un diálogo literario:

No hay nada malo con aquellos sujetos que tienen identidades estratégicas para organizarse alrededor de causas políticas. Es absolutamente adecuado para mí ser dominicano y a la vuelta decir que soy latinoamericano. Cualquiera que trate de vender la idea de que sólo se puede ser una cosa, es porque plantea la pregunta precisamente siendo hostiles contra nuestra complejidad, entonces la pregunta ¿cuál de estas cosas quieres? ser niega la pregunta que, para mí, es la idea de cómo creamos discusiones que traten con esta tremenda complejidad (Díaz, 2014).

Desde este posicionamiento estratégico descrito por Díaz retorno a Stuart Hall y su eliminación de "garantías en la política". Este diálogo "no es importante en cuanto a lo que está en nuestros genes, sino por lo que está en nuestra historia" (Hall, 1997: 4). Me inclino más por abandonar provincialismos que separan y dividen para considerar la idea de Glissant de que "la erranza es una poética, que siempre infiere en el mismo momento que es dicha. El cuento de la erranza es el cuento de la Relación" (Glissant, 2006: 18). Al considerar la "Relación", Glissant hace un acertado diagnóstico de la erranza como principio guía fundamental para los hijos de la diáspora, obligados a seguir una "huella" como vestigio único en la reconstrucción de la memoria: "Que la idea de huella se adhiera, por oposición, a la idea de sistema, igual que una erranza que orienta. Sabemos que es la huella lo que nos pone a todos, vengamos de donde vengamos, en Relación" (Glissant, 1997: 22). Glissant identifica en la huella los espacios a los que los africanos deportados al nuevo mundo tuvieron que recurrir en rebelión para relacionarse: "Esos africanos de la trata que iban a las Américas llevaron consigo, 
allende de las Aguas inmensas, la huella de sus dioses, de sus hábitos, de sus lenguas" (Glissant, 2006: 22).

Las fronteras no se atraviesan con una distinción epidérmica, son el resultado de la acumulación de experiencias como las que Handelsman recupera de Blas Jiménez:

(...) la afirmación racial como acto de solidaridad entre los negros del mundo. Debemos comprender que esta reivindicación racial no es una vuelta ni un vivir en el pasado, pero sí un darnos cuenta de que no somos europeos y que no tenemos que sentirnos europeos para ser hombres. Somos antes que nada negros; una vez aceptada esa realidad, podemos hacernos universales (Handelsman, 1984: 205).

Esta afirmación de negritud parte del color y entiende el espíritu de solidaridad en reivindicaciones que superan políticas de identidad y se extienden a aceptar la realidad de ser sujeto otro de la modernidad. Se trata de un "otro" que mira al futuro constituyendo un nuevo proyecto.

En las coordenadas geográficas específicas que nos conciernen, existe una larga tradición lírica. Se trata de una poesía primordialmente construida en la métrica de la décima, creada por poetas que por quinientos años de destierro forzado pusieron en esta clave su ingenio y resistencia cimarrona, convirtiendo a la poesía en el depósito de la memoria viva para un pueblo forzado al destierro. Volviendo a Glissant, quien formula desde el horror del pasaje medio entre África y las Américas:

Es por esto que nos quedamos con la poesía. Y a pesar de consentir todas las indisputables tecnologías, a pesar de ver el salto político que ha de darse, el horror del hambre y la ignorancia, conquistar la tortura y la masacre, domar el bulto del conocimiento, controlar finalmente el peso de cada pieza de maquinaria y sus resplandores agotadores, mientras pasamos de una era a la otra — del bosque a la ciudad, de la historia al computador- en trayecto hay algo que aun compartimos: ese murmullo, nube o lluvia o humo pacífico. Nos reconocemos como parte de la multitud, de un desconocido que no nos aterroriza. Lloramos y nuestro llanto es poesía. Nuestros botes están abiertos y los navegamos para todos (Glissant, 2006: 9).

La lírica constituye una fisura o grieta desde donde es posible proponer lecturas otras, novedosas, desestabilizadoras e insurgentes. Estos espacios son oportunidades para la transformación, como la plantea Catherine Walsh: "Las grietas se convierten en el lugar y el espacio desde donde avanza la acción, la militancia, la resistencia, la insurgencia y la transgresión; es donde se construyen alianzas que son así inventadas, creadas y construidas" (Walsh, 2014). Por las grietas se construyen estrategias que obligan a emplear herramientas teóricas distintas a las convencionales y demandan buscar en "otras" filosofías, saberes y cosmovisiones. La consecuencia lógica es una aproximación al trabajo de pensadores y escritores críticos que se concentren en la producción simbólica que se enmarca en esas fisuras que menciona Walsh. Se trata de una estrategia ética y estética que deriva de lo que el filósofo afro norteamericano de origen jamaiquino, Lewis Gordon, ha denominado Existentia Africana, quien en su reflexión afirma: "Es claro que sin la contribución de pensadores africanos, las reflexiones sobre preocupaciones como la existencia, la ética, la estética, la política, y las humanidades, son en el mejor de los casos un universal falso" (Gordon, 2000: 40).

Este punto ciego convierte la crítica en una limitación fatal en su capacidad interpretativa que cercena una de las experiencias constitutivas de lo que verdaderamente somos. Antonio Preciado -el poeta a secas - se nos presenta con una obra que se enmarca dentro de un canon nacional y extiende su presencia en la ciudad letrada con su oficio de hombre de letras. Estamos hablando de un intelectual, que tal como lo subraya Linda Tuhiwai Smith en su lectura de Fanon, contiene diversas dimensiones:

(...) a artistas, escritores, poetas, profesores, empleados, oficiales, pequeña burguesía y otros profesionales involucrados en producir "cultura". La importancia de los movimientos nacionalistas reside en las habilidades de reclamar, rehabilitar y articular las culturas indígenas y su liderazgo implícito sobre los pueblos como voces que pueden legitimar una nueva conciencia nacionalista (Tuhiwai Smith, 2012: 69).

Preciado se ha desempeñado en casi todas las actividades que menciona Tuhiwai Smith en la cita previa. Es una figura pública que ha actuado en numerosos ambientes, y como poeta laureado, profesor y rector universitario, ministro de cultura y ex-embajador del Ecuador en Nicaragua. Es decir, Preciado es un intelectual que es parte de la clase ilustrada y cuya obra pertenece al canon de las letras ecuatorianas. Aunque 
él insista que "su poesía no se contiene en su negritud", Antonio Preciado es un pionero afrodescendiente en todos estos espacios.

En este sentido esta lectura se detiene en un desgarramiento fundamental: ¿Cómo leer al poeta negro? ¿Cómo leer con el poeta negro? Especialmente cuando Preciado, como ya se ha expuesto, ve su obra como un trabajo que se desenvuelve dentro de la producción literaria latinoamericana sin que su ascendencia africana lo separe en una categoría otra, distinta y particular. Preciado, en este sentido, es ambivalente al discrepar con la idea de que exista un patrón rítmico propio de los poetas negros:

Los poetas (...) de las etnias que sean, tienen personales ritmos, debidos a la carga emotiva de cada uno y al ineludible ceñimiento a la lengua en la cual se escribe, no hay un patrón rítmico que englobe a los poetas negros. Reconozco sí ciertos "dejos escritos" que son afloramientos de reminiscencias ancestrales, de gravitaciones culturales e históricas que, sin embargo, también en cada uno tienen sus peculiaridades. El ritmo marcado, las sonoridades onomatopéyicas de la primera época de la "poesía negra" ya han sido superadas. La predilección por una cierta cadencia interior en el verso libre no es privativa de los poetas negros, eso no nos estereotipa. En su esencia, la poesía no tiene color (Mussó, 2010).

Aunque la poesía no tenga color, la experiencia del poeta racializado se plasma en muchos casos en "dejos escritos" que el propio autor reconoce. Se trata de rasgos en momentos concretos de su obra pero que, en su opinión, no pueden encuadrarla permanentemente en las coordenadas de una producción literaria "para negros". Conviene entonces proponer ciertas categorías en el análisis y la producción literaria que trasciendan la estereotipación y las limitaciones de la idea de la "literatura afro".

Inicio por la obra del poeta Antonio Preciado en sus años de juventud, cuando sus primeros versos, aquellos que el mismo llama negristas, le rondaban la cabeza, y entablaré un diálogo con algunas corrientes que circulaban por el continente. Afirma Preciado: “Por esos días estaba de moda la 'poesía negra, a partir de la diáspora guilleneana y la vigencia de voces como las de Luis Palés Matos, Jorge Artel, Candelario Obeso, Regino Pedroso, Ramón Guirao, etc., y los ecuatorianos Adalberto Ortiz y Nelson Estupiñán Bass, en nuestra lengua" (Mussó, 2010).
Se trata de versos octosílabos rítmicos, predilectos entre los esmeraldeños afrodescendientes. Poemas improvisados en las tibias noches de parranda en Barrio Caliente durante las animadas fiestas conocidas también como jolgorios. Barrio Caliente es el lugar geográfico donde se traducen las experiencias cimarronas en un microcosmos urbano. En efecto, nos dice Preciado, emerge como un espacio donde se conjugan los usos de la gente negra en sus siglos de resistencia:

En Barrio Caliente la gente negra reproducía sus costumbres, sus usos, una fraternidad continua, permanente, muy sólida. Los patios posteriores no tenían límites, sino un árbol, etc. No había ni alambradas ni bardas, pero la gente sabía que de tal árbol a tal árbol, a tal señal de la naturaleza, pertenecía a eso. Y eso se respetaba simplemente por costumbre (López, 2009).

Los protocolos de solidaridad y respeto entre los miembros de la comunidad nos hablan de una estructura de reciprocidad fraterna entre los habitantes del barrio. Un barrio pobre y caluroso en el clima y el temperamento de sus habitantes, quienes desde las memorias ancestrales utilizaron celebraciones y jolgorios como formas de expresión lúdica y re-existencia en medio de las necesidades del día a día.

El espíritu cimarrón se manifiesta a veces en forma de jubilosa fiesta que contradice a las limitaciones de la pobreza, la alegría se convierte en una forma de resistencia en Barrio Caliente. No es de extrañar, por lo tanto, que el vocablo jolgorio diera título al primer poemario de Preciado publicado en 1961. Se trata de poemas en que Preciado considera el color de su piel, celebrando su juventud, mientras empieza a entender la trágica historia de su gente.

En estos poemas inaugurales se reconocen "los ecos" que en realidad se constituyen mucho más que "dejos", como lo quisiera minimizar Preciado. De hecho, el movimiento del negrismo ha agrupado a numerosos escritores hijos de la diáspora alrededor del desafío de entender en qué consiste reconciliar su actividad literaria con las complejidades inherentes a una tradición, una escuela, o una estética predeterminada. En Desde un volcán volando, el escritor esmeraldeño Nelson Estupiñán había advertido sobre el asfixiante riesgo de encerrar la producción poética en un subgrupo exotizado que se reproduce incestuosamente. 
La Poesía Negra, por lo mismo, no podía permanecer en su tradicional recodo, al margen del saludable flujo y reflujo contemporáneos, y su actualización demandaba la salida de la onomatopeya, que la circunscribía a una especie de cuarto sin ventilación, a un recinto sin aire, y le privaba de la amplitud tan necesaria para la universalización (Handelsman, 2011: 6).

La advertencia de Estupiñán Bass es oportuna para prevenir formulismos que contengan a la poesía en un lugar estático. La necesidad de evitar formulismos y buscar el movimiento queda también de manifiesto en otro análisis del poeta esmeraldeño, esta vez citado por el académico Franklin Miranda:

De ahí que no dude en mostrar el peligro que corre lo afroecuatoriano al tener poetas negristas que repiten fórmulas "universales", paralizantes y estereotipados para tratar lo negro en la lírica. De ahí también que constantemente busque nuevas y más honestas formas para rescatar la cosmovisión de su pueblo tanto en la poesía como en la prosa (Miranda, 2004: 82).

Para entender mejor como juega esta tensión para el autor, conviene leer la bitácora de Antonio Preciado, donde mantiene escritos propios y textos que sobre él han escrito otros autores. Apenas se entra, se encuentra con el titular: "El mundo de mi poesía no se agota en la negritud" (Preciado, 2010). El poeta se afirma, se declara influido y marcado, pero no determinado por el color de su piel. Su afirmación lo vincula con W.E.B. Du Bois cuando propone la pregunta fundamental que constituye el "giro hermenéutico, donde ya no importa qué es ser negro, sino qué significa" (Gordon, 2000: 63). La existencia no puede contenerse en el color de la piel; la racialización se convierte en un proceso de dos vías. Por una parte, está el colonizador que clasifica, que organiza con "membretes de piel, pelo y hueso" (Hall, 1997: 6). Por otra, el sujeto racializado que se pregunta el significado de su racialización, algo que no es estático, como lo desarrolla Stuart Hall al señalar que es un "significante flotante". Esto quiere decir que "no hay nada sólido o permanente en el significado de raza. Cambia todo el tiempo, se mueve, se desliza, es por lo tanto faltante" (Hall, 1997: 2). No solo eso, siguiendo a Lewis Gordon, el sujeto de racialización también alterna según la interpretación: "Negro (...) se convierte en una designación que puede ser aplicada a distintos grupos en tiempos diferentes tanto concreta como metafóricamente" (Gordon, 2000: 63). Antonio Preciado responde categóricamente sin renegar de su ancestro.
Primeramente, soy un hombre, luego soy un hombre negro, con determinadas características étnicas que no me abstraen de mi condición esencial de ser humano que comparte con todos sus semejantes dolores y anhelos inherentes a todas las etnias del mundo, y es dentro de esa generalidad que, dialécticamente, en particular y con sus peculiaridades cabe lo que concierne a la negritud; es decir, como parte del todo que inextricablemente la gran humanidad integra. Por eso, mi poesía no se agota en el ámbito de la negritud, sino que entraña el aliento de todo lo humano, las realidades y las voces insustituibles de todos los hombres, que en ella pugnan por expresarse (Mussó, 2010)

La reflexión de Preciado reitera la profunda tensión de cómo se percibe el poeta a sí mismo, que es como humano, ante todo. En consecuencia, la afirmación de su humanidad contrasta con la subsiguiente de reconocerse hombre negro, el mismo que debe enfrentar el proceso de deshumanización y de invisibilización bajo la línea del color. Una línea firme, una frontera que marca y duele, que persiste, como señala Lewis Gordon:

De la división entre negro y blanco, que sirvió como plano para dividir la humanidad. La línea de color es también una metáfora que excede su formulación concreta. La línea de color es también la línea de género, la línea de clase, la línea de la orientación sexual, la línea de la religión-en resumen, es la línea entre identidades normales y anormales (Gordon, 2000: 63)

Es pertinente, de este modo, considerar el desgarramiento de Preciado a partir de la línea de color, manteniendo distancia de la tentación posmoderna de anclarlo de manera simplista en la identidad. Considerar la identidad sería pertinente en cuanto fuera más allá del esencialismo y se complejizara para volverse detonante de un proceso liberatorio. Como lo sustenta Lewis Gordon: “Encontramos la cuestión de la identidad entre las preguntas ontológicas, preguntas sobre el ser, la esencia y el significado-brevemente, la fuerza existencial de la pregunta final, ¿Quién soy yo?" (Gordon, 2000: 65).

El poeta busca la respuesta volviendo a la memoria, una memoria forjada con las enseñanzas que le dieron su madre y su abuela, Elisa Bedoya viuda de Preciado y Francisca Esterilla, dos mujeres de verbo virtuoso de quienes Preciado afirma: "Ella y mi abuela, en medio de su carencia, fueron muy dulces, muy tiernas, muy cariñosas" (López, 2009). La impronta que le dejaron 
está precisamente en sus palabras, la lengua madre, y materia prima con que Preciado ejerce su oficio. Antonio Preciado escribe poemas inspirado por su madre y su abuela, la otra figura fundamental, de quien el poeta cuenta:

Mi abuela Pancha, Francisca Esterilla, una negra analfabeta, campesina, jututa. Jututo en esmeraldeño quiere decir verdadero. Campesina auténtica me llevó de la mano, a veces caminado sobre las aguas, por los ríos de la provincia de Esmeraldas. De ella aprendí muchísimo. Tengo todavía en mi oído sus palabras certeras, precisas, eficaces, reveladoras, hacedoras, cimentadoras de mi consciencia (López, 2009)

La abuela Pancha es su maestra, una mujer afrodescendiente que, por analfabeta y sabia, recurría a la oralidad para contarle los secretos de la montaña y el río al nieto Antonio. Juntos caminaron y hablaron, y de ella sacó esas piezas milimétricas con las que Preciado compone su obra - la reminiscencia- y la abuela también pervive en su memoria, con sus palabras y saberes. Creencias y dolores que salían de su boca, y que el joven Preciado, escuchaba construyendo su propio verbo:

Ya dije alguna vez

que ella tenía la boca llena de santos

y ángeles de la guarda.

(Preciado, 2006: 301)

Preciado nos introduce en su verso figuras míticas que son parte de la religiosidad popular, normalmente encargadas de proteger la casa y a sus habitantes. Se trata de personajes en quienes se confunden el santoral católico y el panteón ancestral africano:

me hizo falta agregar que también le cabían, con mucha holgura, todas las cosas del pasado; (Preciado, 2006: 301)

La abuela Pancha fue sobre todo una intérprete para Antonio, un nexo con el mundo de los ancestros marcado por el crimen inmenso, visible detrás del manto sincrético al que se acostumbraron las miradas del Nuevo Mundo. Las imágenes de los siguientes versos son evidencia de ello, la sucesión de tambores y avemarías apunta a un entramado espiritual en el que es posible leer las dos tradiciones:

su cielo a su manera, que le oía

aquellas mescolanzas de cantos y tambores cogidos de las manos con las avemarías (Preciado, 2006: 301)

En la figura de "mescolanza" que nos presenta en el verso anterior, se percibe una filtración que le viene al poeta de los labios de su abuela, que con honestidad y verbo virtuoso marcaron el sino de Preciado, quien en su obra buscará descifrar el significado de esta superposición de tradiciones. El poeta reconoce las huellas y las presenta con igual valía; las plasma en estos versos como elementos que se relacionan en igualdad de jerarquía en su cosmovisión espiritual:

intentando entender si ella vivía

con el alma en la boca

o la boca en el alma.

(Preciado, 2006: 301)

El desgarramiento del poeta crece al reconocer en tensión las tradiciones que se entretraman, obligándolo a convivir abiertamente con estos elementos constitutivos diversos. A través de su quehacer poético, negociará esta tensión y potenciará su re-existencia como humano integral.

En su constante evolución en el ejercicio poético, Preciado nos deja testimonio de los distintos estadios de sus preocupaciones, incluyendo el tema afro y el significado que tiene en su existencia. Un interesante contraste en este respecto puede ser leído en el poema que le dedica al activista esmeraldeño Juan García Salazar, a quien le escribe unos versos publicados en el poemario Jututo: Algunos de los míos del año 1996. Preciado nos presenta un poema donde introduce la pasión y el compromiso de vida de su amigo, el obrero del proceso de comunidades negras Juan García Salazar. Preciado describe un compromiso ineludible, de los que "duelen" y que recorre las venas de García:

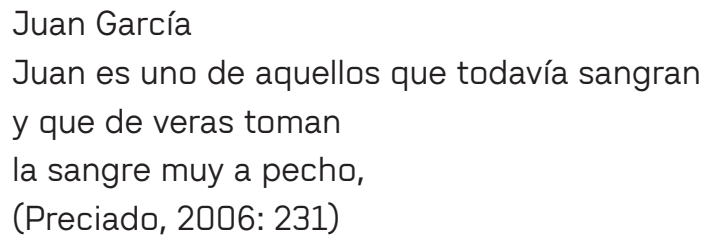

El poeta hace la revelación de que Juan García buscó entablar con Preciado otra de sus rutas hacia esa memoria ancestral. Una memoria que retorna a la esclavitud, al África de los ancestros, y que ahora es preciso buscar y re-crear, en protección de los territorios que constituyen 
las comunidades cimarronas del norte de Esmeraldas, y que constituyen el proyecto de la Gran Comarca.

\section{Alguna vez le dio}

por husmear palmo a palmo en mis alrededores

buscando las pisadas de un esclavo

que hizo la hazaña de fundar un reino.

(Preciado, 2006: 231)

En estos versos sugiere que García está proyectando en el poeta Preciado una correspondencia con el mítico fundador del Reino de Negros de Esmeraldas. Preciado admite que el hermano Juan le imputa al poeta la responsabilidad de liderar desde ese lugar en el que conviven Barrio Caliente y la ciudad letrada en que se sitúa Preciado. Pero el poeta de 1996 le responde con una rotunda negativa en sus versos:

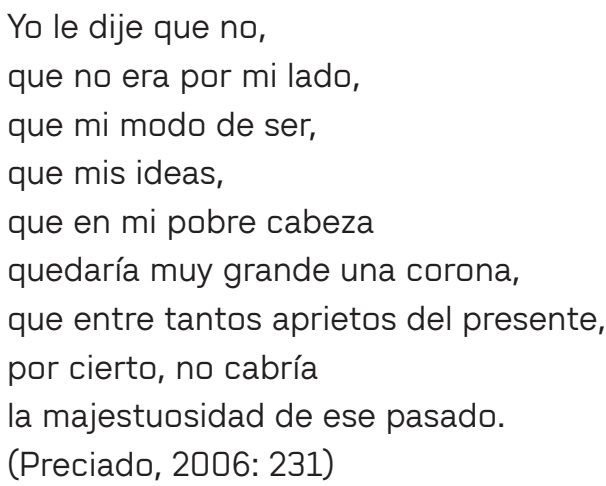

Sin embargo, el terco García se empeña en seguir buscando algo en el poeta y sus palabras. En cada uno de sus versos percibe la posibilidad de que sea él el elegido para continuar la lucha mediante el uso del poder de sus letras. García registra la precisión de su métrica, el peso de cada adjetivo, y la sonoridad de su extensa obra. El hermano Juan reconoce en Antonio Preciado la coincidencia entre Barrio Caliente y la ciudad letrada, considerándola como una oportunidad para adelantar la causa de liderar la construcción metafórica de un nuevo palenque de negros libres en el espacio de las letras contemporáneas ecuatorianas.

Pero él rebuscaba

debajo de las letras de mi nombre, detrás de cada uno de mis pasos,

hasta que supo

que, aparte de ser yo

uno más entre todos los amos y señores

de aquella irreductible parcelita de orgullo,

nada tan solo mío

de modo alguno se ajustaba al caso.

(Preciado, 2006: 232)
El poeta responde obstinado en su negativa para convencer a Juan García que desde su humildad solo puede ser otro obrero más de la lucha. Preciado ve en su quehacer su camino como propio y limitado. Él es "poeta a secas," y es desde sus versos que va a intervenir en una lucha que es la suya propia. Para el Preciado de 1996 el conflicto radica en la poética y la tensión entre la ciudad letrada y Barrio Caliente, en su contexto de escritor ecuatoriano que quiere ser leído en sus propios términos.

El poema es al mismo tiempo respuesta y homenaje. Nos remite a la multiplicidad con que construye su poética traducida en la multiplicidad de Juan García como personaje polisémico al que lee lleno de ideas en su "cabeza bullidora" donde converge la "sabiduría de la gente sencilla". Preciado cierra nostálgico con una consideración sobre el paradero del amigo, especulando sobre sus iniciativas presentes, convencido de su continua lucha en los "negrores" y con la certeza de que su contagiosa energía lo tendrá rodeado de ecos de su propio esfuerzo, metiendo fuego en los corazones de quienes continuaran su lucha y, deseándole donde quiera que el hermano Juan esté, que sienta su fraternal abrazo.

hace mucho no sé por dónde anda, atareado en qué pieles intentando senderos, perdido en qué negrores palpita, y sin embargo, por su repleto corazón, espero que haya ido dejando latidos desgranados que su sombra todavía no haya recogido, y que, por ese olvido, lo reencuentre este abrazo.

(Preciado, 2006: 233)

En la consideración del tema afro vemos como la dimensión política en el trabajo de Antonio Preciado está en tensión con su dimensión poética. De esta forma quiere desmarcarse de un esencialismo que sugiere que sea leído como poeta "negro" o que su lucha se inmiscuya con la de los afrodescendientes en el Ecuador en una forma pre-dispuesta o estereotipada. En este sentido Preciado es capaz de maniobrar desde los márgenes sin jamás ocultar los tintes de su pensamiento, sin jamás renegar del color de su piel. Puede volver a las sonoridades ancestrales negristas, puede sumar su voz por las reivindicaciones políticas, territoriales y culturales que él elija y puede asumir su proyecto de vida enfrentando su desgarramiento 
propio llegando siempre, en las líneas de sus versos, a su propio destino. En sus poderosos versos nos remite a la lucha ancestral por la supervivencia, ecos en los que resuena el coro de la resistencia colectiva —unidad y multiplicidad - un camino andado que es tan largo como la distancia que existe entre la ciudad letrada y Barrio Caliente, que, aunque superado, marca para siempre el proyecto de vida, un territorio que es físico e imaginado. Sus métodos no están condicionados ni por el color de su piel, ni por la textura de su pelo, ni por la composición ósea. Sus condiciones vienen dadas por una memoria ancestral que en su poesía le permite re-crearse y re-existir. En este sentido leo su alineación con aquello que Sylvia Wynter denominó "autopoiesis" como una opción para renovar la propia humanidad.

Sylvia Wynter nos muestra la imposición de una "autopoiesis" nueva. Nuestro entendimiento del proceso causará una nueva ruptura de gran magnitud que nos permitirá dejar nuestra concepción del presente del hombre. Mientras la poética, en nuestra concepción presente se confina a "la ociosidad de las humanidades en la academia occidental"—o a un "llamado", y es entendida como una "cosa no una acción ni un evento", la poética sería alternativamente considerada como la acción mediante la cual el trabajo humano es capaz de renovarse (Gagne, 2007: 252).

La poética de Antonio Preciado transgrede, irrumpe en la ciudad letrada, antagonizando con nociones fijas de espacio, de ideología y, sobre todo, de raza. Es una poesía de suyo decolonizadora desde que reinscribe la humanidad y lo hace sin caer frente a las tentaciones posmodernas de anclarse en las políticas de raza. Su proyecto va mucho más allá, convirtiendo la poética en vehículo de la existencia. El desgarramiento de Preciado nos conecta con el existencialismo de Fanon, desbaratando los discursos con un minucioso cuestionamiento de los métodos: "No vengo armado de verdades decisivas. Mi consciencia no está atravesada por fulgores esenciales. Sin embargo, con total serenidad, creo que sería bueno que se dijeran ciertas cosas" (Fanon, 2009: 41). Y si hay que decir verdades, mejor que sean dichas con versos, versos que más que respuestas traen preguntas, preguntas propias, muy sentidas y por eso mismo válidas. El verso es una forma de entrar en diálogo, en este caso un diálogo definido en la palabra escrita, que es la única reconocida por el estamento letrado.

Ahora la ciudad letrada se ha visto avocada a lidiar con el desgarramiento del poeta Antonio Preciado. Si las normas le fueron impuestas al poeta, este es capaz de tomarlas, apropiarse de ellas y presentar su exploración propia. La poesía se adentra en el abismo interior que, a su vez, enhebra la cultura y la historia de un pueblo, resaltando la poética de la relación que nos anuncia Glissant y que ha servido para construir este diálogo con la obra de Antonio Preciado: "Sabemos que el Otro está entre nosotros y afecta como evolucionamos, así como el bulto de nuestras concepciones y el desarrollo de nuestra humanidad" (Glissant, 1997: 27). En esta trayectoria, en este nomadismo que va de lado a lado, de época en época, de amigo en amigo, del Barrio Caliente a la ciudad letrada, desde la periferia hacia el centro, la poesía y la poética hacen política, interviniendo con el compás de las aguas de los navíos que zozobraron en la costa cargados de esclavos, con cada gota de agua larga, de los torrenciales aguaceros de Barrio Caliente.

\section{Referencias:}

Abad, Gustavo (2013). "Juan García y Juan Montaño: territorios distintos y narrativas complementarias desde la memoria afrodescendiente". Revista Chasqui No 120

Díaz, Junot (2014). "Keynote Speech". North Carolina Literary Festival. Hunt Library Multipurpose Room

Dussel, Enrique (1993). "Eurocentrism and Modernity" (Introduction to the Frankfurt Lectures), Boundary 2, Vol. 20, No. 3, The Postmodernism Debate in Latin America. Duke University Press. https://doi. org/10.2307/303341

Fanon, Franz (2009). Piel negra, mascaras blancas. Madrid: Ediciones Akal.

Gagne, Karen (2007). "On the Obsolescence of the Disciplines.

Frantz Fanon and Sylvia Wynter Propose a New Mode of Being Human, Human Architecture: The Journal of the Sociology of Self-knowledge, 5.

Glissant, Édouard (2006). Tratado del Todo-Mundo. Barcelona: El Cobre Ediciones. (1997). Poetics of Relation. University of Michigan.

Gordon, Lewis R. (2000). Existentia Africana Understanding Africana Existential Thought. Routledge, NY. 
Michael Handelsman (2011). "Antonio Preciado, poeta de la diáspora" en Guaraguao, 38

(2011b). "Nelson Estupiñán Bass:

en contexto" en Guaraguao, 38,

Hall, Stuart (1997). "Race the Floating Signifier".

Entrevista de Sut Jally. Northhampton: Media Education

Foundation.

Iton, Richard (2008). In Search of the Black Fantastic: Politics and Popular culture in the Post-Civil Rights

Era. Nueva York: Oxford University Press, Inc. https:// doi.org/10.1093/acprof:oso/9780195178463.001.0001

López, Modesto (2009). Entre Cantos y Marimbas. Antonio Preciado Poeta. Ediciones Pentagrama, DVD.

Lugones, María (2008). Colonialidad y género. Bogotá: Tabula Rasa, No.9.

Miranda, Franklin; Ortiz, Adalberto y Nelson Estupiñán Bass. "Hacia una narrativa afroecuatoriana. Tesis de Magíster en Literatura Hispanoamericana y Chilena". Universidad de Chile.

Mussó, Luis Carlos (2010). Entrevista realizada para el libro La orilla memoriosa. Marzo 25 de 2010.

Antonio Preciado (2010). Poeta Antonio Preciado (blog).

(2006). Antología Personal. Casa

de la Cultura Ecuatoriana Benjamín Carrión.

Smith, Linda Tuhiwai (2012). Decolonizing

Methodologies. Research and Indigenous Peoples. Zed.

Walsh, Catherine (2014). "Pedagogical Notes from the Decolonial Cracks," emisférica, No. 11, vol. 1.

Wynter, Sylvia (1994). "No Humans Involved. A Letter to my Colleagues". Forum NHI. Knowledge for the 21st Century, Vol.1 No.1. 